\title{
A Clinical Study of Long-Term Administration of Dextran Sulfate (MDS Kowa) in Patients with Retinopathy
}

\author{
G. Mimura, M. Fukuda, ${ }^{*}$ Y. Haraguchi $\dagger$ and T. \\ JINNOUCHI $\dagger$
}

Second Department of Internal Medicine and Department of Ophthalmalogy, Faculty of Medicine, University of the Ryukyus Ryukyus 902, Central Laboratouy, and $\dagger$ Department of Internal Medicine, School of Medicine, Kurume University, Kumume 830, Japan

\begin{abstract}
Mimura, G., Fukuda, M., Haraguchi, Y. and Jinnouchi, T. A Clinical Sutdy of Long-Term Administration of Dextran Sulfate (MDS Kowa) in Patients with Retinopathy. Tohoku J. exp. Med., 1983, 141, Suppl., 389-402-We administered MDS at a daily dose of $1,800 \mathrm{mg}$ to 25 patients with diabetic retinopathy for periods ranging from 12 to 48 months (mean : 28 months) and achieved the following results : 1) During the administration period total cholesterol, triglyceride and fibrinogen levels were all maintained at significantly lower levels. 2) Eye fundus findings showed an improvement in $38.9 \%$ no change in 47. $2 \%$ and a deterioration in $13.9 \%$ of the cases. 3) No side-effects or abnormalities in clinical findings were observed in any of the cases even though clinical tests of hepatic function, renal function, blood chemistry, and urinalysis were conducted. The above results demontsrate that MDS has a marked effect on diabetic retinopathy, especially in cases with moderate to severe symptoms during the non-proliferative stage.—retinopathy; dextran sulphate; cholesterol ; triglyceride; fibrinogen
\end{abstract}

Diabetic retinopathy can be charaterized as an obstructive vascular disorder and during its progressive stages, a reduction in fibrinolysis and an increase in blood fibrinogen occur, which lead to a tendency for intravascular blood coagulation. In recent years, the view has generally prevailed that during the initial rapid stages of proliferative retinopathy, the pathological condition is quite similar to that in DIC, and anticoagulant therapy has therefore been seen as the most likely means of treating this disease with chemotherapy ${ }^{1)}$. Dextran sulfate has been gaining attention as a heparinoid substance and not only does it normalize coagulation and fibrinolysis but it has also been found to normalize lipid metabolism and so is highly regarded as a drug with great promise in the treatment of diabetic retinopathy. Nonetheless, few reports have been published describing the results of long-term treatment with this drug. The authors conducted a study of the therapeutic effects of this drug on diabetic retinopathy. A 
TABLE 1. $A$

\begin{tabular}{|c|c|c|c|c|c|c|c|}
\hline $\begin{array}{c}\text { Cases } \\
\text { No. }\end{array}$ & Sex & Age & $\begin{array}{l}\text { History } \\
\text { (Y) }\end{array}$ & $\begin{array}{l}\text { Adminis- } \\
\text { tration } \\
\text { period } \\
(\mathrm{M})\end{array}$ & Control & $\begin{array}{l}\text { Diabetes } \\
\text { therapy }\end{array}$ & Complication \\
\hline 1 & $F$ & 51 & 6 & 39 & Good & Lente insulin $20 \mathrm{U}$ & Cataract \\
\hline 2 & $\mathrm{~F}$ & 57 & 9 & 38 & Good & Glibenclamide $1 \mathrm{~T}$ & \\
\hline 3 & $\mathrm{~F}$ & 54 & 10 & 48 & Good & Glibenclamide 3T & \\
\hline 4 & $F$ & 69 & 23 & 22 & Good & Glibenclamide $2 \mathrm{~T}$ & \\
\hline 5 & F & 62 & 10 & 23 & Good & Glymidine- $\mathrm{Na} 2 \mathrm{~T}$ & $\mathrm{EH}$ \\
\hline 6 & M & 60 & 3 & 33 & Good & Glibenclamide $2 \mathrm{~T}$ & \\
\hline 7 & $\mathrm{~F}$ & 52 & 5 & 36 & Good & Glibenclamide $0.5 \mathrm{~T}$ & \\
\hline 8 & M & 73 & 11 & 29 & Good & Glibenclamide $2 \mathrm{~T}$ & $\mathrm{EH}$ \\
\hline 9 & $\mathrm{~F}$ & 43 & 3 & 38 & Good & Glibenclamide 1T & Hypertension \\
\hline 10 & M & 76 & 15 & 32 & Good & Glibenclamide $2 \mathrm{~T}$ & \\
\hline 11 & $\mathrm{~F}$ & 74 & 7 & 24 & Good & Glibenclamide IT & $\mathrm{EH}$ \\
\hline 12 & M & 62 & 10 & 26 & Good & Glibenclamide 3T & DN \\
\hline 13 & $\mathrm{~F}$ & 40 & 10 & 24 & Good & Lente insulin $36 \mathrm{U}$ & \\
\hline 14 & $\mathrm{~F}$ & 66 & 4 & 18 & Good & Dietetics & EH, Hyperlipemia \\
\hline 15 & $\mathrm{~F}$ & 46 & 11 & 26 & Good & Glibenclamide $3 \mathrm{~T}$ & $\mathrm{DN}$ \\
\hline 16 & M & 55 & 14 & 24 & Good & Glibenclamide $3 \mathrm{~T}$ & IHD, Hyperlipema \\
\hline 17 & $\mathrm{~F}$ & 80 & 20 & 26 & Good & Glibenclamide $1 \mathrm{~T}$ & EH, Hyperlipemia \\
\hline 18 & M & 54 & 4 & 21 & Poor & Glibenclamide $\mathrm{IT}$ & Liver cirrhosis \\
\hline 19 & $\mathrm{~F}$ & 52 & 5 & 26 & Good & Glibenclamide $2 \mathrm{~T}$ & EH, Hyperlipemia \\
\hline 20 & $\mathrm{~F}$ & 40 & 12 & 31 & Good & Lente insulin $36 \mathrm{U}$ & \\
\hline 21 & M & 29 & 14 & 24 & Fair & Dietetics & \\
\hline 22 & M & 57 & 13 & 31 & Poor & Glyclopyramide $3 \mathrm{~T}$ & \\
\hline 23 & $\mathrm{~F}$ & 60 & 10 & 25 & Poor & Glibenclamide $3 \mathrm{~T}$ & \\
\hline 24 & M & 80 & 22 & 24 & Poor & Buformin $6 \mathrm{~T}$ & \\
\hline 25 & M & .48 & 10 & 12 & Good & Dietetics & \\
\hline
\end{tabular}


List of Case

\begin{tabular}{|c|c|c|c|c|c|c|}
\hline \multirow{2}{*}{ Anamnesis } & \multirow{2}{*}{$\frac{\text { Eye }}{\text { RL }}$} & \multicolumn{3}{|c|}{$\begin{array}{l}\text { Modified Scott } \\
\text { classification }\end{array}$} & \multicolumn{2}{|r|}{ Funduscopic improvement } \\
\hline & & before & during & after & $\begin{array}{l}\text { Judge- } \\
\text { ment }\end{array}$ & Comments \\
\hline \multirow[t]{13}{*}{ Cesarotory } & $\mathrm{R}$ & IIIb & $\mathrm{IIa}$ & $\mathrm{Vb}$ & - & Blot-vitreous hemorrhage $\uparrow$ \\
\hline & $\mathrm{R}$ & IIa & $\mathrm{II} \mathrm{a}$ & $\mathrm{IIa}$ & \pm & \\
\hline & $\mathbf{R}$ & IIIa & $\mathrm{II} a$ & $\mathrm{IIa}$ & + & $\begin{array}{l}\text { Dot-blot hemorrhage } \\
\text { Soft-hard exudatel } \downarrow\end{array}$ \\
\hline & $\mathbf{R}$ & IIIb & IIIa & $\mathrm{IIa}$ & + & $\begin{array}{l}\text { Soft exudate } \downarrow \\
\text { Vascularization } \downarrow\end{array}$ \\
\hline & $\mathbf{R}$ & IIb & IIIb & IIIb & - & $\begin{array}{l}\text { Hard exudate } \uparrow \\
\text { Vascularzation } \uparrow\end{array}$ \\
\hline & $\mathbf{R}$ & $\mathrm{Ia}$ & $\mathrm{IIa}$ & $\mathrm{Ia}$ & \pm & \\
\hline & $\mathbf{R}$ & IIb & $\mathrm{II} a$ & $\mathrm{IIa}$ & + & $\begin{array}{l}\text { Microaneurysm } \downarrow \\
\text { Vascularization } \downarrow\end{array}$ \\
\hline & $\mathrm{R}$ & $\mathrm{IIa}$ & $\mathrm{Ia}$ & $\mathrm{Ia}$ & + & Soft exudate $\downarrow$ \\
\hline & $\mathbf{R}$ & IIIb & IIIlb & IIIb & \pm & \\
\hline & $\mathrm{R}$ & $\mathrm{Ia}$ & $\mathrm{IIa}$ & IIIb & - & $\begin{array}{l}\text { Blot-minute hemorhage } \uparrow \\
\text { Soft exudate } \uparrow\end{array}$ \\
\hline & $R$ & IIIb & IIIa & IIIa & + & $\begin{array}{l}\text { Soft-confluent exudate } \downarrow \text { Vascular- } \\
\text { ziation } \downarrow\end{array}$ \\
\hline & $\mathrm{R}$ & IIIb & IIa & IIa & + & $\begin{array}{l}\text { Confluent exudate } \downarrow \text { Venous defor- } \\
\text { mity } \downarrow\end{array}$ \\
\hline & $\mathrm{R}$ & IIIa & III & III a & \pm & \\
\hline \multirow[t]{2}{*}{ Hypertension } & $\mathrm{R}$ & IIa & $\mathrm{IIa}$ & $\mathrm{IIa}$ & \pm & \\
\hline & $\mathrm{L}$ & IIa & $\mathrm{IIa}$ & IIa & \pm & \\
\hline \multirow[t]{21}{*}{ IHD } & $\mathrm{R}$ & IIIa & IIIa & $\mathrm{Ia}$ & + & $\begin{array}{l}\text { Minute hemorhage } \downarrow \\
\text { Soft exudate } \downarrow\end{array}$ \\
\hline & $\mathrm{L}$ & IIa & $\mathrm{IIIa}$ & $\mathrm{Ia}$ & + & Soft exudate \\
\hline & $\mathrm{R}$ & Ila & IIIa & II $a$ & \pm & \\
\hline & $\mathrm{L}$ & IIa & IIIa & $\mathrm{II} a$ & \pm & \\
\hline & $\mathrm{R}$ & IIIb & IIIb & IIIb & \pm & \\
\hline & $\mathrm{L}$ & $\mathrm{IIIb}$ & IIIb & IIIb & \pm & \\
\hline & $\mathrm{R}$ & IIIa & $\mathrm{IIa}$ & Ia & + & Soft exudate $\downarrow$ \\
\hline & $\mathrm{L}$ & $\mathrm{IIa}$ & $\mathrm{IIa}$ & $\mathrm{II} \mathrm{a}$ & \pm & \\
\hline & $\mathrm{R}$ & $\mathrm{IIa}$ & IIIa & Ia & + & Hard exudate $\mid$ \\
\hline & $\mathrm{L}$ & IIIa & IIIa & $\mathrm{II} \mathrm{a}$ & + & $\begin{array}{l}\text { Dot hemorrhage ! } \\
\text { soft exudate ! }\end{array}$ \\
\hline & $\mathrm{R}$ & IIIa & IIIa & $\mathrm{IIa}$ & + & $\begin{array}{l}\text { blot hemorrhage } 1 \\
\text { Soft exudate } \downarrow\end{array}$ \\
\hline & $\mathrm{L}$ & IIIa & IIIa & IIIb & - & Vacularization $\uparrow$ \\
\hline & $\mathrm{R}$ & IIIa & IIIa & IIIa & \pm & \\
\hline & $\mathrm{L}$ & IIIa & IIIa & IIIa & \pm & \\
\hline & $\mathrm{R}$ & $\mathrm{Ia}$ & $\mathrm{Ia}$ & $\mathrm{IIa}$ & - & Soft exudate $\downarrow$ \\
\hline & $\mathrm{L}$ & IIa & Ia & $\mathrm{Ia}$ & + & Microaneurysm $\downarrow$ \\
\hline & $\mathrm{R}$ & IIIa & IIIa & IIIa & \pm & \\
\hline & $\mathrm{L}$ & IIIa & IIIa & IIIa & \pm & \\
\hline & $\mathrm{R}$ & $\mathrm{IIa}$ & 0 & $\mathrm{IIa}$ & \pm & \\
\hline & $\mathrm{L}$ & $\mathrm{IIa}$ & $\mathrm{IIa}$ & $\mathrm{IIa}$ & \pm & \\
\hline & $\mathrm{R}$ & IIIa & IIIa & $\mathrm{IIa}$ & + & $\begin{array}{l}\text { Minute hemorrhage } \downarrow \\
\text { Snft ovwdato }\end{array}$ \\
\hline
\end{tabular}


daily dose of 1,800 mg MSD kowa tablets was administered to 25 diabetic patients (36 eyes) suffering from retinopathy of slight to moderate severity, and the results are reported.

\section{Subjects and Methods}

\section{Subjects}

As shown in Table 1. time since onset of diabetes ranged from 3 to 25 years with a mean onset time of 10 years in the 25 patients selected as subjects of this study. There were 10 male and 15 female patients ranging in age from 29 to 80 years with a mean age of 57.5 . A breakdown by therapy shown there were 3 patients undergoing only diet therapy, 19 patients taking oral hypoglycemic drugs and 3 patients on insulin. Control before drug administration and during the coarse was evaluated using both the fasting blood glucose value, the blood glucose $2 \mathrm{hr}$ after a meal and the evaluation criteria of Mimura. Control was found to be excellent in 4 cases, good in 15 cases, fair in 1 case and poor in 5 cases. Before treatment, eye fundus findings were classified according to the modified Scott method as ranging from Ia to IIIb, as shown in Table 2.

TABLE 2. Retinopathy severity classification

\begin{tabular}{|c|c|}
\hline $\mathrm{Ia}$ & Microaneurysm and/or dot hemorrhage \\
\hline II a & $\begin{array}{l}\text { Several ( } 2 \text { to } 3 \text { ) blot hemorrhages and hard exudates in } \\
\text { addition to condition Ia }\end{array}$ \\
\hline IIIa & $\begin{array}{l}\text { Increased number (no less than 5) of or enlarged (more than } \\
\text { half of papilla) } \\
\text { blot hemorrhages and hard exudates }\end{array}$ \\
\hline $\mathrm{Ib}$ & $\begin{array}{l}\text { Venous ectasia and deformity or vascularization in addition to } \\
\text { condition Ia }\end{array}$ \\
\hline $\mathrm{IIb}$ & $\begin{array}{l}\text { Venous ectasia and deformity or vascularization in addition to } \\
\text { condition IIa }\end{array}$ \\
\hline IIIb & $\begin{array}{l}\text { Soft exudate minute hemorrhage venous ectasia and deformity } \\
\text { or vascularization in addition to condition IIIa as well as } \\
\text { definite confluent exudate }\end{array}$ \\
\hline
\end{tabular}

\section{Methods}

Administration method. MDS Kowa tablets (each tablet containing $300 \mathrm{mg}$ of sodium dextran sulfate (MDS) were administered in divided doses three times a day after meals, two tablets at each administration. The period of administration ranged from 12 to 48 months with an average of 28 months.

Evaluation of eye fundus findings. In all patients the posterior polar region of both eyes was photographically recorded on color eye fundus photos (posislides). Two to six photos were taken at one time with an eye fundus camera.

Blood biochemistry tests. Blood glucose, urine tests and body weight were determined every 2 to 4 weeks during hospital visits. Total cholestrol, triglyceride and fibrinogen were determined as a rule every 3 months. As in other diabetic patients, hepatic function, renal function and hematopoietic function were tested every 6 months.

\section{RESULTS}

We continuously administered MDS for a period of 12 to 48 months to a total of 36 retinopathic eyes and, as shown in Table 3 , stage improvement was observed 
in 14 eyes (12 cases), and stage deterioration was observed in 5 eyes (5 cases). Thus the improvemont rate was $38.9 \%$ and the deterioration rate was $13.9 \%$. In all other cases there was absolutely no change. These results are analyzed in more detail below.

\section{Therapeutic effect classified by severity}

Table 4 presents a comparison of therapeutic results classified according to severity. Although half of the cases at stage IIIa exhibited improvement, not a single case at stage Ia showed improvement and indeed two Ia cases showed deterioration. Four eyes representing a third of the cases at stage II showed improvement and no cases showed deterioration. Only one case at stage IIIb showed deterioration. Although there were only two IIb cases, one exhibited improvement and one deterioration.

Therapeutic effect classified by eye fundus findings

Table 5 shows the changes in the eye fundus lesions in the 14 improved eyes and the 5 deteriorated eyes. Findings included improvement of soft exudates in

TABLE 3. Funduscopic improvement

\begin{tabular}{ccccc} 
& Improved & Unchanged & Aggravated & Total \\
\hline $\begin{array}{c}\text { Number } \\
\text { of eyes }\end{array}$ & 14 & 17 & 5 & \\
$(\%)$ & $(38.9)$ & $(47.2)$ & $(13.9)$ & 36 \\
\hline
\end{tabular}

TABLE 4. Improvement by severity

\begin{tabular}{ccccc}
\hline Severity & Improved & Unchanged & Aggravated & Total \\
\hline IIIb & 3 & 3 & 1 & 7 \\
IIIa & 6 & 5 & 1 & 12 \\
IIb & 1 & 0 & 1 & 2 \\
IIa & 4 & 8 & 0 & 12 \\
Ia & 0 & 1 & 2 & 3 \\
Total & 14 & 17 & 5 & 36 \\
\hline
\end{tabular}

TABLE 5. Improvement by symptom

\begin{tabular}{lcc}
\hline \multicolumn{1}{c}{ Symptom } & Improved & Aggravated \\
\hline Soft exudate & 11 & 3 \\
Hard exudate & 6 & 2 \\
Blot hemorrhage & 6 & 2 \\
Minute hemorrhage & 4 & 0 \\
Vascularization & 3 & 2 \\
\hline
\end{tabular}


11 eyes (disappearance in 5), disappearance of minute hemorrhaging in 4 eyes (all cases), and improvement of blot hemorrhaging in 6 eyes (disappearance in 4) and in 3 cases neovasculation became narrower and smaller than before treatment, and barely recognizable by ophthalmoscopy (Figs. 1 and 2). Findings of deterioration included an increase in soft exudates in 3 eyes, and an increase in hard exudates, minute hemorrhaging and neovasculations in each of two eyes. However, no eye showed deterioration in minute hemorrhaging. Also vitreous and the appearance of proliferative fibrotic tissue were each observed in 1 eye of the

a


Fig. 1. a: Typical annular retinopathy and many hard exudates were observed before treatment with dextron sulphate.

b: This photo was taken 18 months after the treatment with dextron sulphate, annular retinopathy disappeared and hard exudates decreased remarkably. 
deteriorating cases.

\section{Therapeutic effect classified by chemical control}

As shown in Table 6, of the 19 cases with good control (27 eyes) improvement was seen in 11 eyes $(41 \%)$ and deterioration in 4 eyes $(15 \%)$. In the cases with poor control (9 eyes), improvement was seen in 3 eyes (35\%) and deterioration in 1 eye $(10 \%)$. Thus no significant difference was observed between these two groups. Also, there was no significant difference in effectiveness between male and female patients, and no significant age difference was observed in the effectiveness of MDS.

TABLE 6. Improvement by control

\begin{tabular}{lcccc}
\hline Control & Improved & Unchanged & Aggravated & Total \\
\hline Good & 11 & 12 & 4 & 27 \\
Fair $~$ Poor & 3 & 5 & 1 & .9 \\
Total & 14 & 17 & 5 & 36 \\
\hline
\end{tabular}

The effect of MDS on lipid metabolism

Effect of MDS on total cholesterol. As shown in Fig. 1, the mean total cholesterol level before administration of MDS was $252.8 \pm 14.6$ (M \pm s.E.) $\mathrm{mg} / 100$ $\mathrm{ml}$ and 3 months after starting treatment it was significantly reduced to $206 \pm 15$. $2 \mathrm{mg} / 100 \mathrm{ml}$. During the entire administration period it showed various degrees of reduction in comparison to the pretreatment value (Fig. 1a). The mean value during the final treatment period for all cases was $194.5 \pm 16.5 \mathrm{mg} / 100 \mathrm{ml}$ so that a significant reduction was maintained in comparison to the pretreatment period. (Fig. 1b).

Effect of MDS on triglyceride. As shown in Fig. 2 the mean triglyceride level before administration of MDS was $159.1 \pm 19.5 \mathrm{mg} / 100 \mathrm{ml}$ and within 3 months of starting administration it fell to $109.7 \pm 15.6 \mathrm{mg} / 100 \mathrm{ml}$ showing a significant improvement. As in the case of total cholestrol, triglyceride maintained this low level throughout the entire trial period. (Fig. 2a). The mean value for all cases during the final administration period was $102.4 \pm 11.8 \mathrm{mg} / 100 \mathrm{ml}$ showing a significant reduction in comparison to the pretreatment value (Fig. $2 \mathrm{~b}$ ).

Effect of MDS on plasma fibrinogen. The mean value for plasma fibrinogen before administration of MDS was, as shown in Fig. $3,352.8 \pm 14.4 \mathrm{mg} / 100 \mathrm{ml}$ and within 3 months of administration it showed a significant reduction to $285.6 \pm 11$. $4 \mathrm{mg} / 100 \mathrm{ml}$. Thereafter, the fibrinogen level remained below pre-treatment levels for the entire course of treatment (Fig. 3a). The mean fibrinogen level at the final period of administration was $260.1 \pm 11.2 \mathrm{mg} / 100 \mathrm{ml}$, which was significantly lower than the pretreatment level. (Fig. $3 \mathrm{~b}$ ).

Side-effects and clinical test results. Although we administered MDS over a 




$\mathrm{b}$

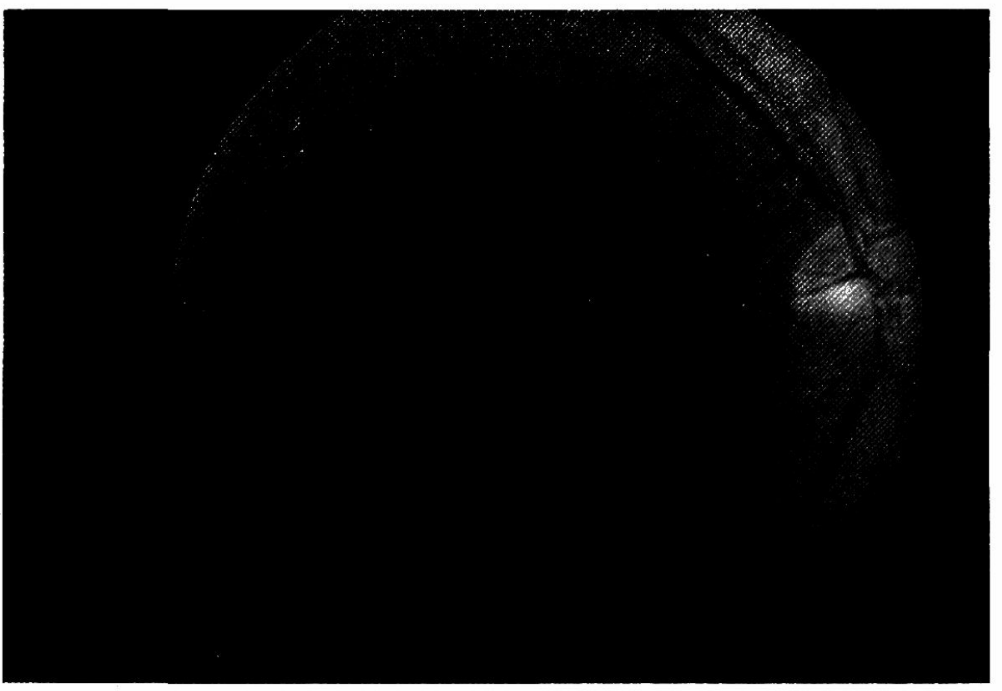

Fig. 2. a : Blot hemorrhages, retinal edema and hard exudates were obseved before treatment with dextran sulphate.

$\mathrm{b}$ : Twenty two months after the starting the admisistration of dextran sulphate, edema and hemorrhages disappeared.

long period of time, no clinical side-effects and no abnormalities in clinical test results were observed, including hepatic function tests (GOT, GPT, AL-P), renal function (BUN, creatinine), blood tests, (hemoglolin, hematocrit value, RBC, $\mathrm{WBC}$, platelet count) urinalysis (sugar, protein, urbilinogen) etc.

\section{Discussion}

Diabetic retinopathy occurs with increasing frequency as the period since onset of diabetes increases, and it has been recognized as clinically necessary for 


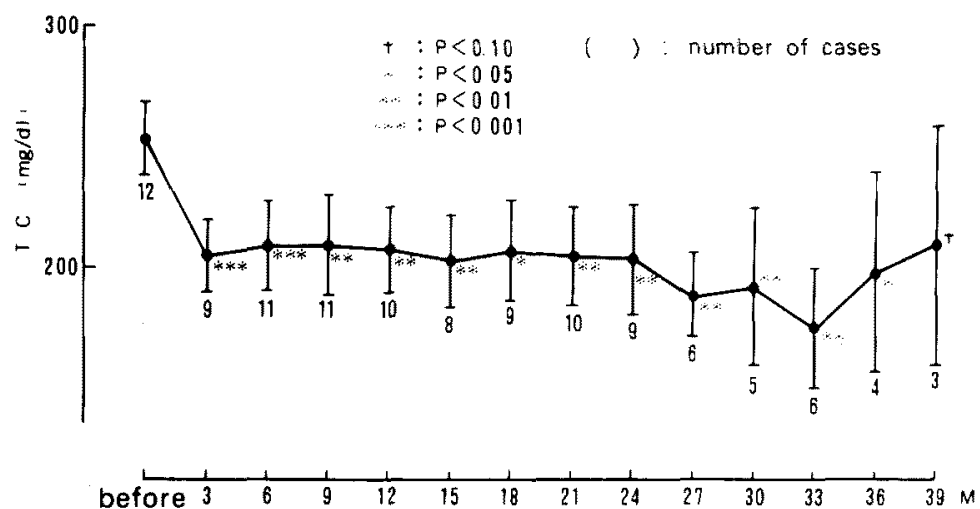

(a)

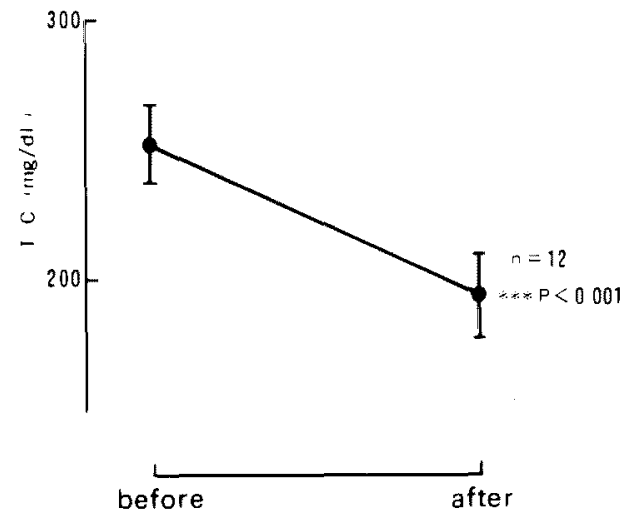

(b)

Fig. 3. Effect of dextran sulfate on total cholesterol.

the maintenance of good control of the course of diabetes to prevent the progress of diabetic retinopathy. At present the causative factors of diabetic retinopathy are still not well understood. Although diabetes is thought to develop due to an insufficiency of insulin activity, it is not clear by what mechanism insulin insufficiency promotes diabetic microvascular disorders, but during the initial stages of retinopathy, debilitation of the capillaries occurs and it is thought that, at the time of proliferative retinopathy, blood coagulation is accelarated ${ }^{4}$. In the case of diabetes, changes occurring during the initial stages in the retinal blood vessels include an increase in vascular permeability and subsequently an increase in aggregability due to thromboxane $A_{2}$ wcich is thought to lead to thrombus formation. It is, however, still unclear by what mechanism insulin insufficiency promotes vascular permeability. Clinically, during the course of diabetes, an increase in coagulability and platelet aggregation and a decrease in fibrinolysis are observed and these conditions become more severe as retinopathy progresses. Thus in the past, hemostyptics were used in the treatment of diabetic retinopathy but these drugs were found to be harmful rather than helpful. It is thought, 

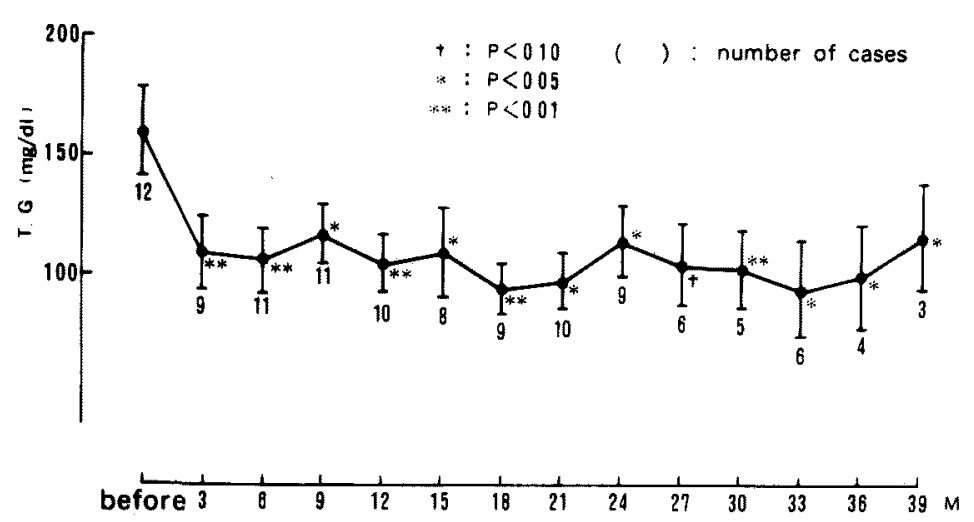

(a)
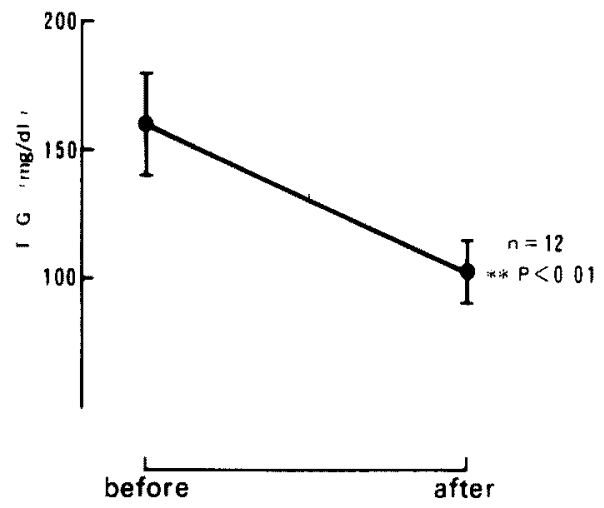

(b)

Fig. 4. Effect of dextran sulfate on triglyceride.

however, that vascular reinforcers such as adrenochromic and flavinoid preparations are effective in treating retinopathy ${ }^{5}$. If we consider this matter from the standpoint of the pathological physiology of retinopathy as described above, a drug with a pharmacological action promoting fibrinolysis and inhibiting platelet aggregation would be the rational drug for treating retinopathy. MDS is a heparinoid type drug and Brown $^{7}$., Cohen et al. ${ }^{8)}$ have indicated that it has a blood lipid cleaning action. Many clinical studies have been performed on MDS to evaluate its action in correcting lipid metabolism and other authors have reported MDS's effect on fibrinolysis including Obuchi et al. ${ }^{9)}$, Matsuoka et al. ${ }^{10)}$, Koike et al. ${ }^{11)}$ Kamei et al. ${ }^{12)}$ and Abe et al. ${ }^{13)}$. We ${ }^{14)}$ studied MDS using the crossover method and found that MDS significantly reduced triglyceride, and tended to reduce total cholesterol, and to decrease the amount of fibrinogen. A significant stimulation of fibrinolysis was observed with the plasminogen free plate method (Eug. + SK) and also a tendency for MDS to stimulate fibrinolysis was observed both with the fibrin standard plate method (Eug. + SK), and the plasminogen free plate method (Eug.). The reduction in triglyceride is considered to be due to a 


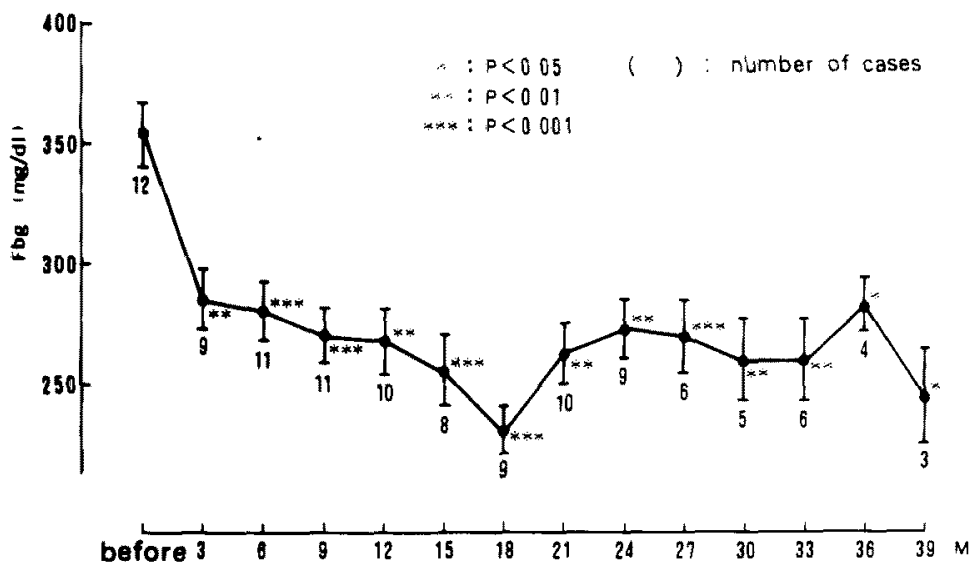

(a)

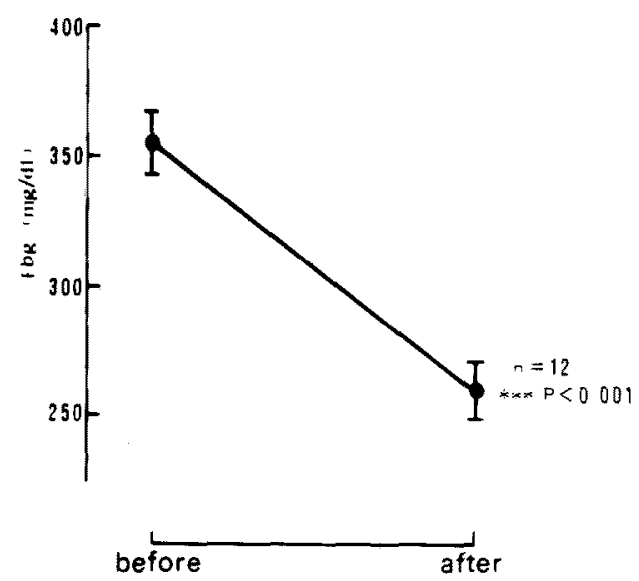

(b)

Fig. 5. Effect of dextran sulfate on plasma fibrinogen.

reinforcement of lipoprotein lipase activity, and the improvement in fibrinolysis is probably caused by a reinforcement of plasminogen activator activity which is thought to be induced by MDS. Hirayama et al. ${ }^{15}$ stated that administration of MDS at a daily dose of $1,800 \mathrm{mg}$ significantly reduced platelet aggregation. Koike et al. ${ }^{11)}$ reported, however, that administration of MDS at a daily dose of 1 , $800 \mathrm{mg}$ had no effect on platelet adhesion or aggregation but that it acted significantly to normalize cases showing excess platelet adhesion. Thus based on these results, MDS can be considered to be a drug that can be clinically applied to diabetic retinopathy. Koike administered MDS at a daily dose of $1,800 \mathrm{mg}$ for a period of 6 months to 22 patients and based on eye fundus findings he reported that it produced improvement in 9 cases, deterioration in 1 case and evaluation was not possible in 3 cases. Kamei administered MDS at a daily dose of $900 \mathrm{mg}$ to 17 patients and $1,800 \mathrm{mg}$ to 21 patients for a period of 2 years. During this 
period, no aggravation or new outbreak of retinopathy occurred, and two cases improved from a rating of Scott III to Scott II. Mine ${ }^{16)}$ administered MDS in daily doses ranging between 900 and $1,350 \mathrm{mg}$ to 7 patients with a rating of Scott IIa and above for 18 months. Since in these five cases, normal fibrinolysis was maintained and no progress in the retinopathic condition was observed, he conjectured that MDS exhibited an effect in cases where the amount of fibrinogen increased bringing about a reduction in fibrinolysis. Yamamoto ${ }^{17)}$ evaluated the efficacy of MDS based on fundus findings and visual acuity in 15 patients to which he administered MDS at a daily dose of $900 \mathrm{mg}$ over a period of 6 months. He discontinued administration to cases that showed no response after 6 months but an effect was observed in 10 patients (administration for 6 to 8 months). Based on Wagener's classification, MDS proved to be effective in 7 out of 9 cases at stages I and II with slight symptoms and in 3 out of 6 cases at stages III and IV with severe symptoms. In the patients with slight symptoms an improvement in the retinopathy was observed and the efficacy rate was especially high in those patients with good chemical control. Ooka et al. ${ }^{18)}$ also administered 6 capsules of MDS per day (1,800 mg) to 15 patients over a period of 6 to 60 weeks and reported the following results. According to eye fundus findings, MDS was markedly effective in 6 cases, effective in 6 cases and no change was seen in 3 cases. In ten patients at Wagener's stage III, it was markedly effective in 4 , effective 3 and ineffective in 3 cases. Three cases improved from Wagener III to II, and 1 case improved from Wagener IV to II. Since MDS administration is known to be effective in cases with serious symptoms, these improvements in eye fundus findings are presumed to be attributable to MDS. Above we have briefly recapitulated various clinical trials describing the effect of MDS on diabetic retinopathy and MDS can thus be clinically evaluated as effective in the treatment of retinopathy. In this study, we administered MDS over a long term and studied its effect on the eye fundus, lipids, and fibrinogen. In regard to eye fundus findings, we periodically took photos of the eye fundus and they were objectively evaluted by Dr. Fukuda. However, the evaluation of our results is a little difficult since we did not establish a placebo control group. In regard to lipids, total cholesterol and triglyceride levels were significantly lower during the entire trial period and the same effect was seen with fibrinogen. These results confirm the efficacy of MDS on the lipid metabolism and coagulation system. Kakamura et al. ${ }^{19)}$ have observed a tendency for HDL-cholesterol to increase during MDS administration. Since most of our cases ranged from subjects with moderate symptoms or above during the non-prolifer-ative or pre-proliferative stage (III B) and our results show an improvement rate of $39 \%$ and a deterioration rate of only $14 \%$, the efficacy of MDS can be considered as verified. After more than a year of treatment, the improvement rate was 9 eyes $(50 \%)$ and the deterioration rate was only 2 eyes $(10 \%)$ in cases at stages IIIb and IIIa. Thus our findings during this period support the therapeutic effectiveness of MDS and agree well with the results 
of Ooka et al. ${ }^{18)}$. In contrast to this, although the number of cases with slight symptoms at stage Ia is quite small, still no improvement was observed and some cases were seen to deteriorate, so MDS does not appear to act effectively during the initial stage of retinopathy, but begins to display its efficacy when vascular obstructive lesions have become evident. Its period of greatest efficacy seems to begin with the appearance of moderate symptoms, starting at the non-proliferative stage of retinopathy.

However, Yamamoto and Ooka et al. ${ }^{18)}$ have observed that MDS acts effectively even in cases with slight symptoms, so it appears to be necessary to study the effect of MDS on a larger number of cases with slight symptoms in the future in order to resolve this issue. Since improvement based on individual findings showed a reduction or disappearance in soft exudates, minute hemorrhaging and blot hemorrhaging, ability of this drug to improve vascular lesions and blood conditions during the period of vascular obstruction and thrombus formation is strongly suggested by these results. The disappearance of neovasculation is thought to be due to the same pathological principles. Since in some cases deterioration was observed, therapy with MDS has limitations. The improvement in hard exudatds is thought to be related to MDS's effect on improving lipid metabolism. In this study, glucose control was not seen to produce any significant effect on the course of the disease, indicating that improving factors unrelated to the control of diabetes intervened, giving further confirmation of the effectiveness of this drug. No difference in efficacy was observed between males and females and no age differences were observed, but since the number of elderly patients who showed improvement was relatively small, it seems likely that with increasing age, retinopathic lesions become irreversible. In any case, during long term administration, lipid metabolism in diabetic patients was observed to improve, fibrinogen level declined and retinopathy improved in $39 \%$ of the cases without a single case showing any side-effect. It can therefore be said that the clinical utility of MDS was confirmed.

\section{References}

1) Fukuda, M. (1972) Blood fibrinolytic activity and fibrinogen concetration in diabetic retinopathy. Eye, Ear, Nose \& Throat Monthly, 51, 266-272. (Japanese)

2) Yamada, K. et al. (1962) Clinical use of heparin and heparinode. Saishin Igaku, 17, 2605. (Japanese)

3) Mimura, G. et al. (1968) Significance of fasting blood sugar in chemical control of diabetes mellitus. (Second Report). Jap. clin. Report, 2, 960-966. (Japanese)

4) Tachii, T. (1968) Studies on hemorrhagic diathesis in diabetes mellitus with special reference to coagulation in Retinopathia diabetica. Bull. Inst, constit, Med, Kumamoto Univ., 18, 199-246. (Japanese)

5) Tanaka, K. (1980) Diabetic retinopathy and intravessel coagulation. In: 15th Medical Meeting of Coagulation and Fibrinolysis, Fukuoka.

6) Uyama, M. \& Yasunaga, K. (0000) Blood coagulability and fibrinolytic activity in retinal hemorrhage. A preliminary report. In diabetic retinopathy and retinal vein 
occlusion. Fol. ophthal. jap., 23, 61-74.

7) Brown, W.D. (1952) Inhibition of alimentary by anticoagulants. Ouart. J. exp. Physiol., 37, 75.

8) Cohen, H. \& Tudhope, G.R. (1950) Dextran Sulphate: Use as an anticoagulant, and action in lowering serum cholestrol. Brit. med. $J$., 2, 1023.

9) Oobuchi, S. et al. (1967) Study on blood fibrinolytic activity of Dextran Sulphate. Rinsho to Kenkyu, 55, 1019. (Japanese)

10) Matsuoka, Sh. et al. (1973) Experimental study on coagulability and fibrinolytic activity of dextran sulphate. Clin. Haematol., 14, 882-890. (Japanese)

11) Koike, K. et al. (1980) Influence of dextran sulphate on lipid, thrombocyte function, coagulabity and fibrinolytic activity of diabetics with retinopathy. Rinsho to Kenkyu, 57, 605-611. (Japanese)

12) Kamei, I. et al. (1979) Influence of long term administration of Dextran sulphate on lipid and coagulabity and fibrinolytic system of diabetics with retinopathy. Basic Pharmacol. Therap., 6, 3123-3136. (Japanese)

13) Abe, T. (1978) Consideration of hyperlipemic cases with long term administration of MDS (dextran sulphate). Basic Pharmacol. Therap., 6, 3123-3136. (Japanese)

14) Mimura, G. et al. (1976) Clinical study of MDS (dextran sulphate) used by cross over method to patients with hyperlipemia. Igaku no Ayumi, 96, 782-799. (Japanese)

15) Hirayama, T. et al. (1976) Clinical experience of long term administration of MDS Kowa (dextran sulphate) - especially effect of MDS Kowa to coagulability and aggregation of thrombocyte. Basic pharmacol. Therap., 4, 1274-1286. (Japanese)

16) Mine, T. (1975) The progress and the fibrinolytic activity of the diabetic retinopathy treated with Dextran sulphate. Acta soc, ophthal. jap., 79, 371-375.

17) Yamamoto, T. (1969) Clinical observation on diabetic retinopathy - Clinical experience with dextran sulphate. Rinsho Ganka, 23, 123-129. (Japanese)

18) Ooka, Y. et al. (1968) Attempts at medical treatment of diabetic retinopathy. Rinsho Ganka, 22, 1081-1087. (Japanese)

19) Nakamura, H. \& Hara, T. (1978) Metabolic alteration of plasma lipoproteins Changes of lipoprotein compositions by dextran sulphate. Jap. J. Geriatr., 15, 362368. 